\title{
The working of the 1983 Mental Health Act: the experience of patients, relatives, psychiatrists, general practitioners and social workers involved in compulsory admission
}

\author{
LYNNE WEBSTER, Senior Registrar (formerly Research Fellow) University Department of \\ Psychiatry, University Hospital of South Manchester, West Didsbury; and CHRISTINE \\ DEAN, Senior Lecturer, Department of Psychiatry, Queen Elizabeth Hospital, \\ Birmingham B15 2TH
}

The 1983 Mental Health Act was introduced to increase the safeguards of the civil liberties of patients. One of the new provisions is that it is now the statutory responsibility of hospital managers to inform detained patients of their rights; this is done by giving them a leaflet explaining the appeal procedures. Doubt has been expressed (Dunlop, 1979) about whether this is an efficient means of conveying information to acutely ill patients.

It is possible that increasing safeguards of the civil liberties of patients may be at the cost of suffering to the patient because treatment is more difficult to administer; tightening of the criteria for the use of emergency orders might cause delays and difficulties for patients, relatives and the professionals who administer the Act. It has also been feared that the new rights of appeal for patients on observation orders might cause psychiatrists to choose the more restrictive treatment order more often (Szmukler, 1983). We found that although the number of observation orders remained unchanged there were less emergency orders and more treatment orders than under the 1959 Act, indicating a shift in the direction of more restrictive orders (Webster et al, 1987).

The change in the role of the social worker under the new Act may result in differences in opinion between professionals; the social worker now has to "satisfy himself that detention in hospital is the most appropriate way of providing the care and medical treatment of which the patient stands in need" and also to consider all possible community-based alternatives to hospital care. A study of the interaction between professional groups using the 1959 mental health legislation (Bean, 1980) demonstrated a high concordance between the ratings of psychiatrists and social workers for severity of illness and dangerousness to others. It is possible that the change in brief of the social workers may result in disharmony between the professionals with social workers not making appplications despite having two medical recommendations.
The current study investigates the success of the new measures in the 1983 Mental Health Act in informing the patients of their rights and also examines whether or not the tighter regulations result in delays in the patient obtaining treatment and in disagreements between professionals using the Act.

\section{The study}

A sample of 90 compulsorily detained patients was drawn from three hospitals in Greater Manchester, between August 1983 and December 1985. Three different types of hospital were chosen to gain as representative a sample as possible. Thirty consecutive compulsorily detained patients were studied from each hospital. This included all patients who were detained on Sections 2, 3 or 4. Two weeks after compulsory admission the patients were asked about their experience of being detained and were given a brief test of their level of knowledge of their rights under the 1983 Act.

The psychiatrist involved in each case rated the patient for dangerousness, suicide risk and capability of coping outside hospital (vulnerability) using 4point scales. These ranged from "no risk" to "almost certain to attempt suicide" and "completely capable" to "completely incapable". The length of time the patient had been known to the clinical team was recorded. The psychiatrist was asked for details of the admission, including any difficulties in communication or disagreements with other professionals involved, any sources of delay and any harm to the patient or others that arose from a delay. They were also asked why a particular section had been used.

In compulsory admissions using Sections 2 or $\mathbf{3}$, the doctor who signed the second recommendation was interviewed. In nearly all cases this was a general practitioner, either the patient's own or a Section 12 approved doctor asked to examine the patient for the 
purposes of completing the legal documentation. Information about the circumstances of admission and ratings of the patient were obtained using the same format as the psychiatrist's questionnaire, giving the GP's view of the same situation. It was recorded whether the doctor was the patient's own GP or not and how many compulsory detention orders the doctor had signed in the preceding year. The social workers who made the applications were asked to make ratings and give information about their view of the circumstances surrounding admission.

If the patient had a relative who had been involved in the admission or who had been in close contact with the patient prior to admission the relative was interviewed and asked to rate the patient's dangerousness, suicidal risk and vulnerability using the same scales as the professional workers. Additional questions were asked about any difficulties or delays the relative might have experienced with the services and any harm that might have been caused by delays.

\section{Findings}

Data were only available on 79 patients; four had already been discharged and seven were still (two weeks after admission) unable to give an interview because of their disturbed mental state. Twenty-nine patients $(37 \%)$ did not know who had informed them that they were going to be detained and $56(71 \%)$ did not know who, if anyone, had explained the implications of being detained. Of those who did remember being informed $50(60 \%)$ said they had been informed by the psychiatrist.

Seventy $(89 \%)$ remembered having been given the leaflet explaining their rights (according to the hospital records they had all received it). Twenty-six (33\%) of patients actually read the leaflet and $12(15 \%)$ had had someone read it to them and explain the contents. Table I gives the results of the questionnaire asking seven basic facts about the patients' rights; $\mathbf{7 7 \%}$ did not know how or when they could appeal. We found no difference in the levels of knowledge between patients from different hospitals despite different methods being used to deliver the leaflets.
TABLE I

Detained patients replies to questions about their rights weeks after admission $(n=79)$

\begin{tabular}{lc}
\hline Question & $\begin{array}{c}\text { Correct reply } \\
n(\%)\end{array}$ \\
\hline $\begin{array}{l}\text { Can you leave hospital? } \\
\text { Can you be brought back } \\
\text { if you leave? }\end{array}$ & $75(95)$ \\
$\begin{array}{l}\text { How long does your Section last? } \\
\text { Do you have to accept treatment } \\
\text { if you do not want to? }\end{array}$ & $75(95)$ \\
$\begin{array}{l}\text { Can you appeal? } \\
\text { How would you start } \\
\text { an appeal? }\end{array}$ & $58(73)$ \\
\hline
\end{tabular}

Sixty-four patients had relatives who could be interviewed about their admission; 72 GPs, 51 social workers and 25 psychiatrists were involved in the 90 compulsory admissions. In seven out of eight instances where Section 4 was used it was converted to a Section 2 shortly after admission and in these instances the psychiatrist involved in the Section 2 was interviewed. One GP and one social worker refused to be interviewed.

The length of time the professionals knew the patient before completing recommendations for admission are shown in Table II; about one third of the patients had been known to the professionals for less than 24 hours. This table also shows that half of the patients were admitted within 24 hours of having contact with the professionals involved in the admission. Three patients had been known to the professionals for less than 24 hours and had no relative available for consultation. However, the professionals differed from the relatives in their perception of the number of cases where there had been avoidable delay and where harm resulted to the patient or others as a result of that delay (Table III).

The relatives had usually been aware of the problem for some considerable time before admission was finally arranged; in 39 cases $(61 \%)$ they had known

TABLE II

Details of the professionals involvement before compulsory admission

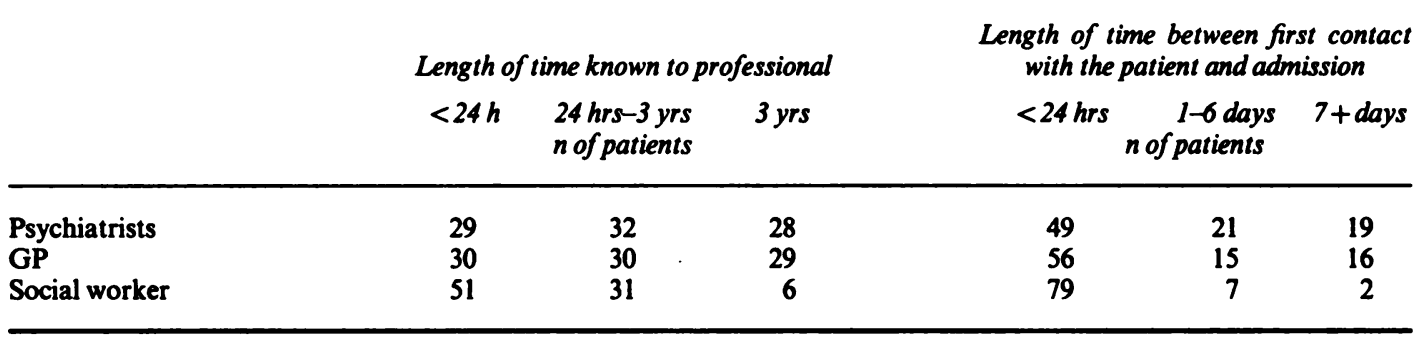


TABLE III

Subjective opinion of avoidable delay and of any harm resulting from delay

\begin{tabular}{lcc}
\hline & $\begin{array}{c}\text { Avoidable delay* } \\
n(\%)\end{array}$ & $\begin{array}{c}\text { Harm to patient or others } \\
\text { as a result of delayt } \\
n(\%)\end{array}$ \\
\hline $\begin{array}{c}\text { Psychiatrist } \\
(n=89)\end{array}$ & $5(5.6)$ & $3(3.4)$ \\
$\begin{array}{c}\text { GP } \\
(n=89)\end{array}$ & $13(14.6)$ & $3(3.4)$ \\
$\begin{array}{c}\text { Relatives } \\
(n=64)\end{array}$ & $19(29.7)$ & $14(21.9)$ \\
\hline
\end{tabular}

*Difference between relatives $\left(\chi^{2} \quad 6.2 P<0.02\right)$ general practitioners $\left(\chi^{2} 4.4 P<0.05\right)$ and psychiatrists $\left(\chi^{2} 14.8\right.$ $P<0.001)$

†Difference between relatives and general practitioners with respect to harm. $\chi^{2} 11.3 P<0.001$

for more than a week and in $12(19 \%)$ of cases more than a month.

The psychiatrists we interviewed did not admit to using Section 3 in preference to Section 2 because of the possibility of an early review tribunal with the latter. However in ten instances they had used Section 2 instead of Section 4 because it had no provision for compulsory treatment. The general practitioners we interviewed could not cite instances where they would have liked to use a Section 4 but the social worker disagreed. The social workers had considered possible alternatives to detention in 16 cases but suitable community facilities were not available.

There was no difference between the three professional groups in their rating of dangerousness or suicide risk, nor between the relatives and the professionals.

\section{Comment}

The fact that two weeks after admission about one third of the detained patients in the study did not know who, if anyone, had given them any explanation of what was happening to them was disappointing. This could have been because they were too ill at the time to register information given to them or it could be that as in Bean's study (1980) no information was given. Although most patients remembered being given the leaflet about their rights, only about one third of patients appeared to have read it, confirming fears that this is not a good way of communicating with severely ill patients (Dunlop, 1979); certainly two weeks after admission one third of patients were ignorant of their rights to appeal and more than two thirds (77\%) did not know how to do so.

The relatives reported avoidable delay and harm to the patient or others in significantly more cases than the professionals. This confirms the suspicion that the new regulations may be resulting in delay causing harm to the patient and their families; in two thirds of cases the relatives had realised there was a problem for more than a week.

There was agreement between the professionals about the degree of dangerousness and suicide risk of the patients detained. This confirms Bean's (1980) finding of a high concordance between professionals and indicates that the new social work powers have not impaired this. However, we were not able to investigate the possibility that some patients were recommended for admission by two doctors and were not admitted compulsorily because of failure of the social worker to make an application, as such patients by definition were not detained. In most cases the statutory responsibility of the social worker to consider alternatives to compulsory detention was a formality; either the patient was too ill to be dealt with in any other setting or alternative community facilities were not available.

The findings of our study are that some aspects of the 1983 Mental Health Act are still a mere formality; the informing of the patient of their rights and the consideration by social workers of alternatives to hospital admission for acutely ill patients. There is also the worry that the new regulations may be causing delay resulting in distress for the patient and their relatives. There are also a number of patients who are being detained without the protection of someone (relatives or professional) knowing them for more than 24 hours.

\section{Acknowledgements}

This study was supported by a generous research grant from the Nuffield Provincial Hospitals Trust. We would like to thank Professor N. Kessel for his advice.

\section{References}

Bean, P. (1980) Compulsory Admissions to Mental Hospitals. Chichester: John Wiley.

Dunlop, J. L. (1979) Review of the Mental Health Act 1959. A doctor's point of view. Royal Society of Health Journal, 99, 213-216.

SZMUKLER, G. (1983) The Mental Health (Amendment) Act 1982: will it make a difference? Bulletin of the Royal College of Psychiatrists, 7, 158-160.

Webster, L., DeAN, C. \& Kessel, N. (1987) Effect of the 1983 Mental Health Act on the management of psychiatric patients. British Medical Journal, 295, 1529-1532. 